\title{
Effects of opioids on human serotonin transporters
}

\author{
M. Barann • U. M. Stamer • M. Lyutenska • F. Stüber • \\ H. Bönisch • B. Urban
}

Received: 24 August 2014 / Accepted: 6 October 2014 / Published online: 22 October 2014

(C) Springer-Verlag Berlin Heidelberg 2014

\begin{abstract}
The serotonin (5-hydroxtryptamine, 5-HT) system plays a role in analgesia and emesis. The aim of this study was to test whether opioids or ketamine inhibit the human 5-HT transporter and whether this increases free plasma 5-HT concentrations. HEK293 cells, stably transfected with the human 5-HT transporter cDNA, were incubated with morphine, hydromorphone, fentanyl, alfentanil, pethidine (meperidine), tramadol, ketamine, and the reference substance citalopram (specific 5-HT transporter inhibitor). The uptake of $\left[{ }^{3} \mathrm{H}\right] 5-\mathrm{HT}$ was measured by liquid scintillation counting. In a second series of experiments, study drugs were incubated with plasma of ten healthy blood donors and change of 5-HT plasmaconcentrations were measured (ELISA). The end point was the inhibition of the 5-HT transporter by different analgesics either in HEK293 cells or in human platelets ex vivo. Tramadol, pethidine, and ketamine suppressed $\left[{ }^{3} \mathrm{H}\right] 5-\mathrm{HT}$ uptake dose-dependently with an $\mathrm{IC}_{50}$ of $1,20.9$, and $230 \mu \mathrm{M}$, respectively. These drugs also prevented 5-HT uptake in platelets with an increase in free plasma 5-HT. Free 5-HT concentrations in human plasma were increased by citalopram $1 \mu \mathrm{M}$, tramadol $20 \mu \mathrm{M}$, pethidine $30 \mu \mathrm{M}$, and ketamine $100 \mu \mathrm{M}$ to $280[248 / 312] \%, 269[188 / 349] \%$, and $149[122 /$
\end{abstract}

M. Barann and U. M. Stamer, these authors contributed equally to this work.

M. Barann · M. Lyutenska $\cdot$ B. Urban

Department of Anaesthesiology and Intensive Care Medicine,

University of Bonn, Sigmund-Freud-Str. 25, 53127 Bonn, Germany

U. M. Stamer $(\bowtie) \cdot$ F. Stüber

Department of Anaesthesiology and Pain Medicine, Inselspital and

Department of Clinical Research, University of Bern,

Freiburgstrasse, 3010 Bern, Switzerland

e-mail: ulrike.stamer@dkf.unibe.ch

H. Bönisch

Institute for Pharmacology and Toxicology, University of Bonn,

Sigmund-Freud-Str. 25, 53127 Bonn, Germany
$174] \%$, respectively, compared to controls without any coincubation (means [95\% CI]; all $p<0.005$ ). No change in both experimental settings was observed for the other opioids. Tramadol and pethidine inhibited the 5-HT transporter in HEK293 cells and platelets. This inhibition may contribute to serotonergic effects when these opioids are given in combination, e.g., with monoamine oxidase inhibitors or selective serotonin reuptake inhibitors.

Keywords Fentanyl $\cdot$ Morphine $\cdot$ Tramadol $\cdot$ Meperidine Ketamine $\cdot$ Serotonin (5-hydroxtryptamine)

\section{Introduction}

The involvement of the serotonin 5-hydroxtryptamine (5-HT) system in analgesia is well described (Millan 2002; Sommer 2006). Previous patch-clamp techniques demonstrated that 5 $\mathrm{HT}_{3}$ receptors are sensitive and specific targets for morphine, less so for hydromorphone, but not for fentanyl-type opioids (Wittmann et al. 2006, 2008). In addition, some opioid analgesics have been suggested to be weak serotonin reuptake inhibitors and to be involved in serotonin toxicity (Boyer and Shannon 2005; Gillman 2005). Thus, the 5-HT transporter constitutes another important component of the 5-HT system. However, publications that clearly describe comparative effects of pethidine (meperidine) and other opioids on serotonin transport using a single methodology are lacking (Gillman 2005).

The 5-HT-transporter is found not only in neurons but also in platelets and in enterochromaffin cells, the latter representing the most important peripheral 5-HT stores. The 5-HT transporter is responsible both for the rapid reuptake of released 5-HT into presynaptic nerve terminals and for the control and maintenance of a low plasma 5-HT level (Schloss and Williams 1998). 
Drugs which inhibit the 5-HT transporter such as selective serotonin reuptake inhibitors (SSRIs) may lead to enhanced plasma and synaptic 5-HT concentrations (Barann et al. 2006 b) which, in turn, may stimulate $5-\mathrm{HT}_{3}$ receptors. This mechanism could explain how emetogenic drugs lacking a direct effect on $5-\mathrm{HT}_{3}$ receptors may still involve them as important players in opioid-related nausea and emesis. The atypical opioid tramadol is an example of a drug that did not affect human $5-\mathrm{HT}_{3 \mathrm{~A}}$ receptors at clinical plasma concentrations, but which potently inhibits the human 5-HT transporter in vitro (Barann et al. 2006a).

The present study investigated the effects of different opioids as well as ketamine, a structurally unrelated drug with strong analgesic properties, on the 5-HT transport and whether this leads to an increase in free plasma 5-HT concentrations. However, there are no in vivo models available so far to investigate 5-HT reuptake. Thus, the well-established culture of HEK293 cells stably transfected with the human 5-HT transporter cDNA and human platelets ex vivo was employed as a surrogate model. The end point of this trial was the inhibition of the 5-HT transporter by different analgesics either in HEK293 cells or, in a second experimental setting, in human platelets ex vivo. The hypothesis was that some of the study drugs inhibit human 5-HT transporters in a manner similar to tramadol, resulting in changes of free 5-HT concentrations in human plasma.

\section{Methods}

Transfection and cell culture

Human embryonic kidney cells (HEK293 cells, $20 \%$ confluent) were stably transfected by the modified calcium phosphate method (Chen and Okayama 1987) with the human 5-HT transporter cDNA, subcloned into the mammalian expression vector pcDNA3 (Invitrogen). Stably transfected cell clones were selected by means of the antibiotic geneticin (G480) and kept in culture as previously described (Barann et al. 2000).

\section{$\left[{ }^{3} \mathrm{H}\right] 5$-HT uptake in HEK293 cells}

Experiments were carried out as described previously with minor modifications (Barann et al. 2006b): HEK293 cells stably expressing the human 5-HT transporter (wild-type sequence of the solute carrier family 6 , member 4 (SLC6A4)) were cultured at $36{ }^{\circ} \mathrm{C}$ on 24 -well cell culture cluster plates. After removal of the growth medium, cells were washed and preincubated with incubation buffer for $20 \mathrm{~min}$. The incubation buffer was composed as following (mM): $\mathrm{NaCl} 125.0$, $\mathrm{KCl} 4.8, \mathrm{MgSO}_{4}$ 1.2, $\mathrm{KH}_{2} \mathrm{PO}_{4}$ 1.2, HEPES 25.0 (4-(2hydroxyethyl)piperazine-1-ethanesulfonic acid), D-glucose 5.55 , ascorbic acid $1.02, \mathrm{CaCl}_{2} 1.3$, and the monoamine oxidase inhibitor pargyline 1.0. Study drugs to be tested for inhibition of $\left[{ }^{3} \mathrm{H}\right] 5$-HT uptake were also present during the 20-min preincubation period. Drug concentrations ranged between $10 \mathrm{nM}$ and $300 \mu \mathrm{M}$. In each experiment, samples incubated with citalopram $(1 \mu \mathrm{M})$, a well-described inhibitor of 5-HT uptake, were introduced as reference and samples without additional drugs served as controls. Subsequently, cells were incubated for $5 \mathrm{~min}$ with buffer containing $10 \mathrm{nM}$ $\left[{ }^{3} \mathrm{H}\right] 5-\mathrm{HT}$. Uptake of $\left[{ }^{3} \mathrm{H}\right] 5-\mathrm{HT}$ was terminated by removal of the incubation buffer and rapidly washing the cells with icecold drug-free incubation buffer. The cells were solubilized in $0.5 \mathrm{ml}$ Triton X-100 (0.1\%). An aliquot of the cell lysate was used for determination of the protein content and the $\left[{ }^{3} \mathrm{H}\right] 5$ HT content of solubilized cells was measured by liquid scintillation counting. Specific $\left[{ }^{3} \mathrm{H}\right] 5-\mathrm{HT}$ uptake was defined as uptake inhibited by the reference substance citalopram $1 \mu \mathrm{M}$ measured in picomole per milligram protein. The $\left[{ }^{3} \mathrm{H}\right] 5-\mathrm{HT}$ uptake in the absence of any drug served as control. For each concentration of the study drugs, at least six experiments were carried out in triplicates.

\section{5-HT uptake in platelets (free plasma 5-HT measurement)}

The experiments were carried out on 24-well cell culture cluster plates (Falcon) at $36{ }^{\circ} \mathrm{C}$. Fifty $\mathrm{ml}$ of whole blood was donated by healthy volunteers (written consent was waived by the ethics committee of the University of Bonn). The blood was treated with heparin (250 units final concentration). In order to improve the signal-to-noise ratio, drug effects on uptake in platelets were measured during addition of $100 \mathrm{nM}$ 5-HT ("spiking"). Spiking was performed by mixing $1000 \mu \mathrm{l}$ human blood plasma with $17.6 \mathrm{ng} / \mathrm{ml} \mathrm{(=100} \mathrm{nM)} \mathrm{5-HT} \mathrm{for} 5 \mathrm{~min}$. In the subsequent experiments, spiked blood samples served as controls.

The protocol for testing the effect of different analgesics on 5-HT serum concentrations involved a timing schedule similar to the $\left[{ }^{3} \mathrm{H}\right] 5-\mathrm{HT}$ uptake experiments described above: blood samples $(1 \mathrm{ml})$ were preincubated for $20 \mathrm{~min}$ at $36{ }^{\circ} \mathrm{C}$ in the absence or presence of the study drugs at concentrations up to $300 \mu \mathrm{M}$ or the reference drug citalopram $1 \mu \mathrm{M}$. Subsequently, samples were incubated for $5 \mathrm{~min}$ with 5 -HT $100 \mathrm{nM}$. At the end of an experiment, blood samples were centrifuged (900× $\mathrm{g}, 4 \mathrm{~min})$ and platelet-free plasma (200 $\mu \mathrm{l}$ aliquots) was separated and stored at $-20^{\circ} \mathrm{C}$.

5-HT concentration of platelet-free plasma was determined by a specific 5-HT ELISA (enzyme-linked immunosorbent assay) test (IBL, Hamburg, Germany) according to the manufacturer's instructions. Samples were measured in duplicates, and a standard curve was created for each plate. The absorbance was read at $450 \mathrm{~nm}$ by an ELISA Reader (Bio-Rad Lab., USA). The results were assessed by calculating the mean concentration of the duplicates with a coefficient of variation of below $12 \%$ was considered acceptable. Minimum detection levels were $0.33 \mathrm{ng} / \mathrm{ml}$. 
Data analysis

Data analysis was performed with STATISTICA 10.0 (StatSoft, Inc. Tulsa, OK, USA) and GraphPad Prism 4 (GraphPad Prism, CA, USA). Concentration-response curves were fitted by the Hill equation: $r=\mathrm{IC}^{n}{ }_{50} /\left(c^{n}+\mathrm{IC}^{n}{ }_{50}\right)$, where $r$ is the normalized response, $c$ is the drug concentration, $n$ is the Hill coefficient, and $\mathrm{IC}_{50}$ is the drug concentration causing the half-maximal effect.

Due to the exploratory character of this study, a power analysis to plan the number of experiments to reach statistical significance was not feasible. At least four experiments were planned for each drug concentration. Results are presented as mean \pm SEM and $95 \%$ confidence intervals [95 \% CI] or mean \pm SD. Comparisons of samples incubated with respective analgesics or the reference citalopram with the controls (no addition of analgesics) were performed using paired $t$ test. Due to multiple comparisons, the level of significance was set to $p<0.005$.

\section{Drugs/solutions}

Citalopram and 5-hydroxytryptamine creatinine sulfate were obtained from Sigma (München, Germany); tramadol was a gift from Grünenthal (Aachen, Germany). [ $\left.{ }^{3} \mathrm{H}\right] 5-\mathrm{HT}$ (specific

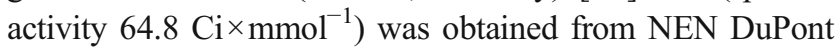
(Dreieich, Germany), alfentanil and fentanyl from JanssenCilag (Neuss, Germany), hydromorphone from Abbott (Wiesbaden, Germany), racemic ketamine (+/- ketamine hydrochloride) from Sigma (München, Germany), morphine sulfate from Mundipharma (Limburg, Germany), and pethidine (meperidine) from Aventis (Bad Soden, Germany). Tramadol concentrations used were recalculated from previous clinical studies (Barann et al. 2006a, b; Grond et al. 1999; Jellinek et al. 1990; Lehmann et al. 1990; Stamer et al. 2007). Opioid and ketamine concentrations were chosen according to a clinically relevant nanomolar plasma concentration range and beyond if no effects were seen at these concentrations (Jeleazcov et al. 2012; Paech et al. 1994; Reves et al. 2011; Urban et al. 2006; White et al. 1980; Wittmann et al. 2008). 5HT solutions were freshly diluted from aqueous stock solutions (stored at $-20^{\circ} \mathrm{C}$ ). Drug stocks were prepared daily.

\section{Results}

Effect of opioids, ketamine, and citalopram on $\left[{ }^{3} \mathrm{H}\right] 5-\mathrm{HT}$ uptake in HEK293 cells

Application of $10 \mathrm{nM}\left[{ }^{3} \mathrm{H}\right] 5$-HT for 5 min to HEK293 cells expressing the human 5-HT transporter resulted in specific $\left[{ }^{3} \mathrm{H}\right] 5-\mathrm{HT}$ accumulation $(2088 \pm 226 \mathrm{fmol} / \mathrm{mg}$ protein). The reference citalopram $1 \mu \mathrm{M}$ suppressed this accumulation by 93.4 [95 \% CI $92.1 / 94.8] \%$ to $145.5 \pm 18.2 \mathrm{fmol} / \mathrm{mg}$ $(p<0.0001)$. Tramadol and pethidine showed a concentration-dependent inhibition of 5-HT uptake with an $\mathrm{IC}_{50}$ of $0.93[0.36 / 1.36] \mu \mathrm{M}$ and $20.9[14.6 / 29.6] \mu \mathrm{M}$, respectively (Fig. 1a). For ketamine, inhibition of specific uptake occurred at higher concentrations with an $\mathrm{IC}_{50}$ of 230.3 [158.4/334.5] $\mu \mathrm{M}$. In contrast, morphine, hydromorphone, fentanyl, and alfentanil did not alter specific uptake at concentrations between $10 \mathrm{nM}$ and $30 \mu \mathrm{M}$ (Fig. 1b).

Effect of opioids, ketamine, and citalopram on 5-HT uptake from plasma into platelets

The basal free plasma 5-HT concentration pooled from all experiments in the absence of any drug (no addition of 5HT) was $10.1 \pm 0.4[9.2 / 10.9] \mathrm{ng} / \mathrm{ml}(57.4 \mathrm{nM}, n=106)$. Spiking, i.e., mixing $1000 \mu$ l human blood plasma with $17.6 \mathrm{ng} / \mathrm{ml}(=100 \mathrm{nM}) 5$-HT for $5 \mathrm{~min}$, resulted only in a slight, nonsignificant increase in free 5-HT concentration up to $12.1 \pm 0.7[10.7 / 13.6] \mathrm{ng} / \mathrm{ml}=68.75 \mathrm{nM} 5$-HT $(p>0.1 ; n=48)$.

The inhibition of the 5-HT transporter of platelets by the different analgesics and citalopram in human spiked plasma are shown in Fig. 2. Free 5-HT concentration was significantly increased in all experiments by the reference substance citalopram $1 \mu \mathrm{M}$ to $31.9 \pm 1.3[29.3 / 34.6] \mathrm{ng} / \mathrm{ml} 5-\mathrm{HT}$. Tramadol and pethidine concentration-dependently elevated
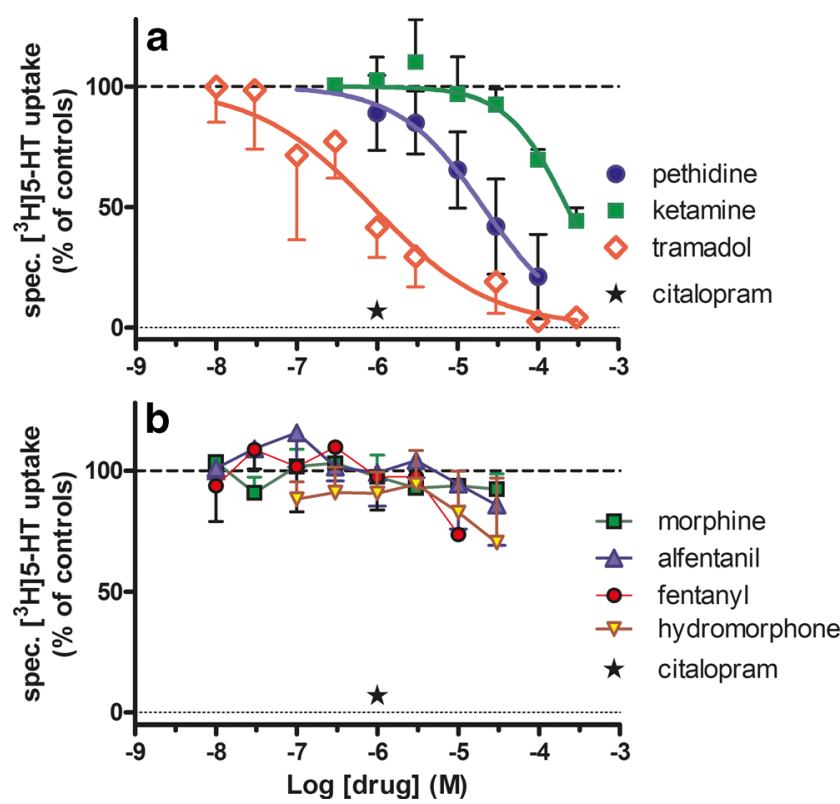

Fig. 1 Effect of citalopram $1 \mu \mathrm{M}$ (strong inhibitor of 5-HT uptake, reference substance), opioids, and ketamine on $\left[{ }^{3} \mathrm{H}\right] 5-\mathrm{HT}$ uptake via the human 5-HT transporter in HEK293 cells stably expressing the human 5HT transporter. Data present \%-changes of $\left[{ }^{3} \mathrm{H}\right] 5$-HT uptake compared to controls (samples without any additional drug) (mean $\pm \mathrm{SD}, n=6-10)$. a Only the atypical opioids and ketamine caused an inhibition of $\left[{ }^{3} \mathrm{H}\right] 5-\mathrm{HT}$ uptake. b For morphine, hydromorphone, fentanyl, and alfentanil, no inhibition of $\left[{ }^{3} \mathrm{H}\right] 5-\mathrm{HT}$ uptake was observed 
free plasma 5-HT (Fig. 2a). For example, incubation with $20 \mu \mathrm{M}$ tramadol yielded 5-HT concentrations of $25.2 \pm 1.7$ [21.4/29.1] ng/ml versus $10.7 \pm 1.9[6.4 / 14.9] \mathrm{ng} / \mathrm{ml}$ for the control $(n=8 ; p<0.0001)$, whereas $30 \mu \mathrm{M}$ pethidine elevated measures from $12.8 \pm 1.5[9.4 / 16.3] \mathrm{ng} / \mathrm{ml}$ for the control to $31.4 \pm 1.2[28.6 / 34.3] \mathrm{ng} / \mathrm{ml}(n=8, p<0.0001)$. Ketamine increased plasma 5-HT concentrations only for the high-dose groups, e.g., for ketamine $100 \mu \mathrm{M}$, a 5-HT concentration of $18.8 \pm 1.3[15.6 / 21.9] \mathrm{ng} / \mathrm{ml}$ was measured $(n=4 ; p=0.003)$. Overall, the reference citalopram $1 \mu \mathrm{M}$ produced an increase of plasma 5 -HT to $280 \pm 16$ [248/312]\% compared to controls (set to $100 \%$ ) of that experiment. For tramadol 1 and $20 \mu \mathrm{M}$, the increase amounted to $133 \pm 21[118 / 148] \%$ and $268 \pm 23$ [215/321] $\%$, for pethidine $30 \mu \mathrm{M}$ to $269 \pm 34$ [188/349]\% and for ketamine $100 \mu \mathrm{M}$ to $149 \pm 11[122 / 174] \%$ compared to the respective controls (Fig. 2a).

In contrast, alfentanil, fentanyl, morphine, and hydromorphone at concentrations up to $10 \mu \mathrm{M}$ had no effect on free 5-HT plasma concentration 5 min after addition of 100 nM 5-HT (Fig. 2b).

Comparison of the effects on the $\left[{ }^{3} \mathrm{H}\right] 5-\mathrm{HT}$ uptake in vitro and on the plasma 5 -HT

The results above show that the drugs tested exert qualitatively similar effects on $\left[{ }^{3} \mathrm{H}\right] 5$-HT uptake in vitro and 5-HT uptake in platelets. To quantitate the correlation between transporter
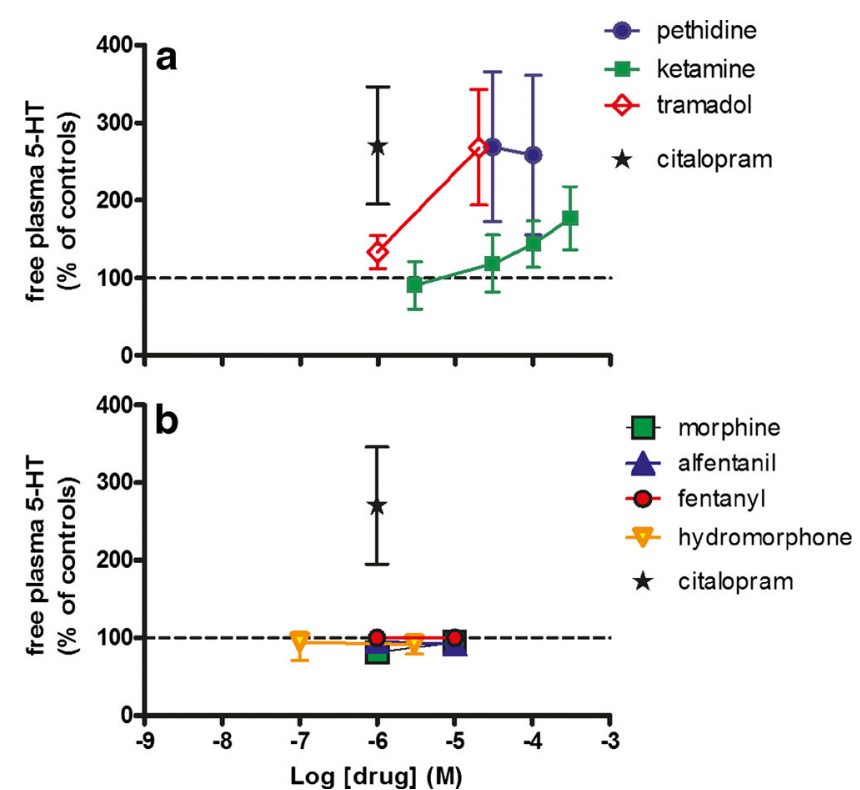

Fig. 2 Effect of citalopram $1 \mu \mathrm{M}$, opioids, and ketamine on free plasma

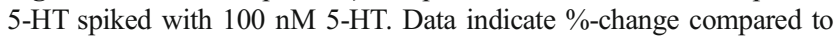
controls without any co-incubation of the respective experiment (mean \pm $\mathrm{SD}, n=4-10$ ). a Only clinically relevant concentrations of tramadol and pethidine caused increases of free plasma 5-HT $(p<0.0001)$. b For morphine, hydromorphone, fentanyl, and alfentanil, no increase of plasma 5-HT concentrations was observed. inhibition and plasma 5-HT concentration, results of the two experimental settings were plotted against each other. The drugs tested had comparable effects on $\left[{ }^{3} \mathrm{H}\right] 5$-HT uptake in HEK293 cell expressing 5-HT transporters and on 5-HT uptake in platelets with a linear relationship (correlation coefficient of 0.9 ; Fig. 3). If only considering the drugs having an effect, correlation coefficient amounted to $0.8(p<0.001)$.

\section{Discussion}

Opioids and the 5-HT transporter

This study confirms that the human 5-HT transporter is a target not only for tramadol (Barann et al. 2006a, b) but also for pethidine. These results were obtained both for the 5-HT transporter expressed in HEK293 cells in vitro as well as for the native 5-HT transporter in platelets ex vivo. The potencies of tramadol, pethidine, and ketamine as transporter inhibitors reported here are low compared to SSRIs used in clinical practice (Gillman 2005). Tramadol and pethidine have been reported before to possess weak serotonin reuptake inhibitory potency (Gillman 2005). Additionally, it has been suggested that tramadol does not only inhibit reuptake but also releases serotonin (Rastogi et al. 2008).

The weak opioid tramadol inhibited uptake, and the results were consistent with the previously published concentrationresponse curves for the enantiomers (Barann et al. 2006a, b). Sufficiently high clinical plasma concentrations for tramadol to substantially block 5-HT uptake are reported after intravenous administration in a perioperative setting (Barann et al. 2006b; Jellinek et al. 1990; Stamer et al. 2007). For pethidine, higher $\mu \mathrm{M}$ concentrations were necessary in this experimental setting to inhibit 5-HT uptake. Paech et al. (1994) described

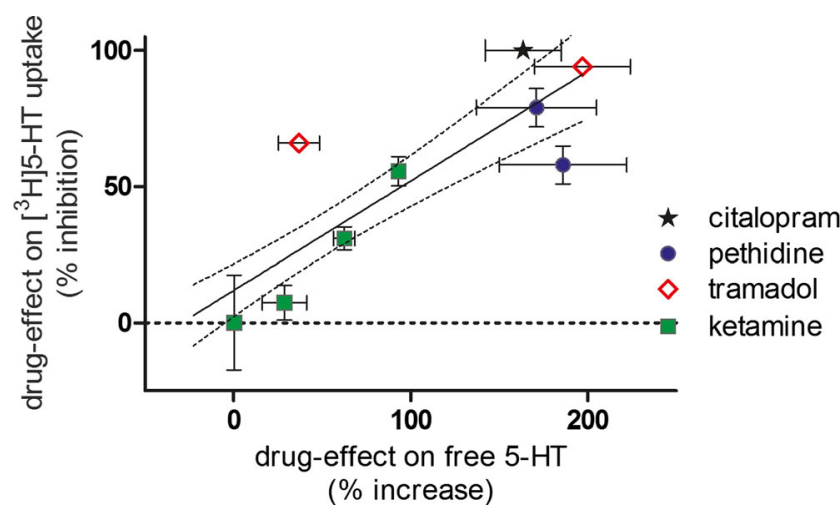

Fig. 3 Comparison of drug effects on $\left[{ }^{3} \mathrm{H}\right] 5-\mathrm{HT}$ uptake and free plasma 5-HT. The mean value for each effect caused by the respective concentration of the same drug is plotted. Solid line, linear regression; slope, 0.4 $\pm 0.05, p<0.0001$; dashed lines, $95 \%$ confidence interval. Drug concentrations and $n$ values are from Figs. 1 and 2. For the drugs showing an influence, the correlation coefficient is 0.83 
plasma concentrations of about $2000 \mathrm{ng} / \mathrm{ml}(\sim 8 \mu \mathrm{M})$ after fast intravenous (i.v.) bolus administration of pethidine $100 \mathrm{mg}$ whereas Koska et al. (1981) used doses of $5 \mathrm{mg} / \mathrm{kg}$ body weight which resulted in plasma concentrations of more than $5000 \mathrm{ng} / \mathrm{ml}(>20 \mu \mathrm{M})$. If considering these large pethidine i.v. bolus doses, accumulation of serotonin by inhibition of the 5 HT transporter seems to be possible in clinical situations, specifically if another serotonergic drug is coadministered. With the FDA-approved dose of $100 \mathrm{mg}$ and the high percentage of drug to be bound to plasma proteins, however, it is unlikely that serotonin concentrations can be increased through relevant inhibition of the 5-HT transporter. Tramadol and pethidine differ substantially from the much more potent "typical" opioids alfentanil, fentanyl, morphine, and hydromorphone. The latter, at below $30 \mu \mathrm{M}$, shows effects neither on the 5-HT transporter expressed in HEK293 cells nor on native 5-HT transporters in platelets, whereas analgesic effects would be observed at concentrations well below $1 \mu \mathrm{M}$ in opioid-naive subjects (Wittmann et al. 2008). For ketamine, effects on 5-HT uptake were only observed for high concentrations exceeding the clinically relevant range (Reves et al. 2011; Urban et al. 2006; White et al. 1980).

While morphine has been ruled out as a serotonin reuptake inhibitor before, there has been uncertainty whether fentanyl may be involved in serotonin toxicity (Gillman 2005). Although older publications suggested fentanyl to be safe, some case reports highlighted serotonin toxicity and fatalities after comedication with monoamine oxidase (MAO) inhibitors or SSRIs (Ailawadhi et al. 2007; Alkhatib et al. 2010; Gollapudy et al. 2012; Gillman 2005; Pedavally et al. 2014; Rang et al. 2008; Rastogi et al. 2008; see also the web reference fentanyl with the warning published by a pharmaceutical company www.akdae.de). It has to be pointed out that concomitant medication of SSRIs or MAO inhibitors with the respective opioids is crucial for symptoms of toxicity to develop, even if each drug is given at therapeutic doses (Bijl 2004; Gillman 2005; Rastogi et al. 2008).

However, the present study could not confirm any relevant effect on $\left[{ }^{3} \mathrm{H}\right] 5$-HT uptake in HEK293 cells and 5-HT uptake in platelets for fentanyl and alfentanil. These findings suggest that not only serotonin reuptake inhibition alone but also other serotonergic effects such as increased availability of the serotonin precursor L-tryptophan, increased serotonin release, decreased serotonin metabolism or agonism at postsynaptic serotonin receptors may contribute to serotonin toxicity (Gillman 2005). Among the latter, the 5- $\mathrm{HT}_{2 \mathrm{~A}}$ receptor is discussed as a critical receptor required for the activation of serotonin toxicity (Boyer and Shannon 2005; Sun-Edelstein et al. 2008). However, none of the before-mentioned mechanisms are known for fentanyl or alfentanil. It remains to be tested whether these opioids may act more potently on heteropentameric $5-\mathrm{HT}_{3}$ receptor subtypes (other than the homopentameric 5- $\mathrm{HT}_{3 \mathrm{~A}}$ receptor) (Niesler et al. 2003).
Furthermore, the 5- $\mathrm{HT}_{2 \mathrm{~A}}$ receptor is discussed as a critical receptor required for activation of serotonin toxicity (Boyer and Shannon 2005; Sun-Edelstein et al. 2008).

The 5-HT transporter inhibition by opioids described here does not seem to correlate with their affinity for opioid receptors since only the atypical opioids pethidine and tramadol inhibited the 5-HT transporter in concentrations which can be measured after intravenous bolus injection (Barann et al. 2006a; Jellinek et al. 1990; Paech et al. 1994; Stamer et al. 2007). This is in line with the previous findings that inhibition of 5- $\mathrm{HT}_{3 \mathrm{~A}}$ receptors by opioid analgesics did not correlate with their affinity for opioid receptors either (Wittmann et al. 2006).

It has to be pointed out that the potential effects of opioid metabolites, which are generated in vivo, might also play a role in drugs' serotonergic effects. An analysis of tramadol enantiomers and their metabolites demonstrated that the $(+)$ and (-)-enantiomer potently suppressed the 5-HT transporter whereas $O$-demethyl-tramadol showed less effects at clinical concentrations (Barann et al. 2006b). Future experiments should also address opioid metabolites, specifically norpethidine which has been reported to cause severe serotonin syndrome-like adverse events.

Citalopram $1 \mu \mathrm{M}$ was employed as the reference drug as it is a well-described potent inhibitor of serotonin uptake with an $\mathrm{IC}_{50}$ value in the low nanomolar range. Nevertheless, it should be noted that citalopram at high micromolar concentrations also inhibits MAO-A (Fisar et al. 2010).

\section{Serotonin concentrations}

The present results suggest that the function of native 5-HT transporters can be assessed in vitro as well as ex vivo. The examined blood samples still contained intact platelets with functional 5-HT transporters, consistent with the observation that first, added "cold" 5-HT was rapidly taken up by the platelets and thus, could not be detected in plasma after $5 \mathrm{~min}$; second, this 5-HT uptake by platelets was inhibited by citalopram, resulting in elevated free 5 -HT concentration.

The comparison of drug-induced inhibition of $\left[{ }^{3} \mathrm{H}\right] 5-\mathrm{HT}$ uptake in cultured cells expressing 5-HT transporters and drug-induced elevation of 5-HT concentrations in human plasma revealed a linear relation between transporter inhibition (in cultured cells or intact platelets) and increases in free plasma 5-HT concentration.

To date, no laboratory tests are available to confirm the diagnosis of serotonin syndrome (Boyer and Shannon 2005; Rastogi et al. 2008; Sun-Edelstein et al. 2008). Serotonin toxicity is considered an intra-synaptic concentration-related phenomenon and, therefore, concentrations in the brain and spinal cord rather than in blood may be relevant (Bijl 2004; Gillman 2014). This fact also indicates the limitations of the study. A surrogate model with HEK 293 cells which can easily be transfected with the human 5-HT transporter as well as 
human platelets ex vivo was used. As this study also demonstrates that it is possible to measure plasma 5-HT concentrations directly with a highly sensitive ELISA technique, future studies could evaluate whether a clinically useful cutoff value for serotonin concentrations associated with toxic symptoms can be defined. Drug effects on free 5-HT concentration in human blood plasma could be tested for correlations with corresponding effects on 5-HT transporters. This approach may prove useful for the description of the kinetics of transitory 5-HT peaks (expected in the minute range) which may occur clinically after fast bolus injection of drugs such as tramadol or pethidine, where nausea and vomiting has been reported following fast bolus injection of these drugs (Jellinek et al. 1990; O’Sullivan 1962).

\section{Conclusions}

Opioid effects on the human 5-HT transporter expressed in HEK293 cells and effects on human 5-HT plasma levels ex vivo are corresponding: drugs which inhibit the transporter in vitro such as tramadol and pethidine (but not alfentanil, fentanyl, hydromorphone, and morphine) also caused an increase of free plasma 5-HT by inhibition of 5-HT uptake in platelets. It has to be determined whether these effects contribute to serotonin-mediated adverse events, e.g., serotonin toxicity, when administered in patients under concomitant MAO inhibitors or SSRIs.

Acknowledgements This study was funded by a grant of the Deutsche Forschungsgemeinschaft (DFG; BA 1454).

We thank Gundula Hesse, Zita Dorner, and Caroline von dem Bussche for helpful technical assistance.

Conflict of interest The authors declare that they have no conflict of interest.

\section{References}

Ailawadhi S, Sung KW, Carlson LA, Baer MR (2007) Serotonin syndrome caused by interaction between citalopram and fentanyl. J Clin Pharm Ther 32:199-202. doi:10.1111/j.1365-2710.2007.00813.x

Alkhatib AA, Peterson KA, Tuteja AK (2010) Serotonin syndrome as a complication of fentanyl sedation during esophagogastroduodenoscopy. Dig Dis Sci 55:215-216. doi:10.1007/s10620-009-0711-x

Barann M, Meder W, Dorner Z, Brüss M, Bönisch H, Göthert M, Urban BW (2000) Recombinant human 5-HT3A receptors in outside-out patches of HEK 293 cells: basic properties and barbiturate effects. Naunyn Schmiedebergs Arch Pharmacol 362:255-265

Barann M, Brüss M, Brinkmann M, Linden I, Lyutenska M, Schneider M, Walkembach J, Wittmann M (2006a) 5-HT3 receptors and emesis. Pharmacol Rep 58:253-255

Barann M, Urban B, Stamer U, Dorner Z, Bönisch H, Brüss M (2006b) Effects of tramadol and O-demethyl-tramadol on human 5-HT reuptake carriers and human 5-HT3A receptors: a possible mechanism for tramadol-induced early emesis. Eur J Pharmacol 531:54-58. doi: 10.1016/j.ejphar.2005.11.054

Bijl D (2004) The serotonin syndrome. Neth J Med 62:309-313

Boyer EW, Shannon M (2005) The serotonin syndrome. N Engl J Med 352:1112-1120. doi:10.1056/NEJMra041867

Chen C, Okayama H (1987) High-efficiency transformation of mammalian cells by plasmid DNA. Mol Cell Biol 7:2745-2752. doi:10. 1128/MCB.7.8.2745

Fisar Z, Hroudová J, Raboch J (2010) Inhibition of monoamine oxidase activity by antidepressants and mood stabilizers. Neuro Endocrinol Lett 31:645-656

Gillman PK (2005) Monoamine oxidase inhibitors, opioid analgesics and serotonin toxicity. Br J Anaesth 95:434-441. doi:10.1093/bja/ aei2 10

Gillman PK. (2014) Monoamine oxydase inhibitors, opiate analgesics and serotonin toxicity. Available: http://www.psychotropical.com/ index.php/moi-oa-st. Accessed 30 March 2014. doi 10.1093/bja/ aei210. PMID: 16051647

Gollapudy S, Kumar V, Dhamee MS (2012) A case of serotonin syndrome precipitated by fentanyl and ondansetron in a patient receiving paroxetine, duloxetine, and bupropion. J Clin Anesth 24:251252. doi:10.1016/j.jclinane.2011.04.017

Grond S, Meuser T, Uragg H, Stahlberg HJ, Lehmann KA (1999) Serum concentrations of tramadol enantiomers during patient-controlled analgesia. Br J Clin Pharmacol 48:254-257. doi:10.1046/j.13652125.1999.00986.x

Jeleazcov C, Saari TI, Ihmsen H, Mell J, Fröhlich K, Krajinovic L, Fechner J, Schüttler J (2012) Population pharmacokinetic modeling of hydromorphone in cardiac surgery patients during postoperative pain therapy. Anesthesiology 120:378-391. doi:10.1097/ALN. 0b013e3182a76d05

Jellinek H, Haumer H, Grubhofer G, Klappacher G, Jenny T, Weindlmayr-Goettel M, Fitzal S (1990) Tramadol in postoperative pain therapy. Patient-controlled analgesia versus continuous infusion. Anaesthesist 39:513-520

Koska AJ, Kramer WG, Romagnoli A, Keats AS, Sabawala PB (1981) Pharmacokinetics of high-dose meperidine in surgical patients. Anesth Analg 60:8-11

Lehmann KA, Kratzenberg TP, Schroeder-Bark B, Horrichs-Haermeyer G (1990) Postoperative patient-controlled analgesia with tramadol. Analgesic efficacy and minimum effective concentrations. Clin J Pain 6:212-220

Millan MJ (2002) Descending control of pain. Prog Neurobiol 66:355474. doi:10.1016/S0301-0082(02)00009-6

Niesler B, Frank B, Kapeller J, Rappold GA (2003) Cloning, physical mapping and expression analysis of the human 5-HT3 serotonin receptor-like genes HTR3C, HTR3D and HTR3E. Gene 310:101111. doi:10.1016/S0378-1119(03)00503-1

O'Sullivan JF (1962) Analgesia for forceps delivery. A technique for the "single-handed" obstetrician. Br Med J 1:151-152

Paech MJ, Moore JS, Evans SF (1994) Meperidine for patient-controlled analgesia after cesarean section. Intravenous versus epidural administration. Anesthesiology 80:1268-1276

Pedavally S, Fugate JE, Rabinstein AA (2014) Serotonin syndrome in the intensive care unit: clinical presentations and precipitating medications. Neurocrit Care 21:108-113. doi:10.1007/s12028-0139914-2

Rang ST, Field J, Irving C (2008) Serotonin toxicity caused by an interaction between fentanyl and paroxetine. Can J Anaesth 55: 521-625. doi:10.1007/BF03016672

Rastogi R, Swarm RA, Patel TA (2008) Case scenario: opioid association with serotonin syndrome: implications to the practitioners. Anesthesiology 115:1291-1298. doi:10.1097/ALN. 0b013e31823940c0

Reves JG, Glas P, Lubarsky DA (2011) Nonbarbiturate intravenous anesthetics. In: Miller RD, Cuchiara RF, Miller ED, Reves JG, 
Roizen MF, Savarese JJ (eds) Anesthesia. Churchill Livingston, Philadelphia, pp 282-372

Schloss P, Williams DC (1998) The serotonin transporter: a primary target for antidepressant drugs. J Psychopharmacol 12:115-121. doi:10. $1177 / 026988119801200201$

Sommer C (2006) Is serotonin hyperalgesic or analgesic? Curr Pain Headache Rep 10:101-106

Stamer UM, Musshoff F, Kobilay M, Madea B, Hoeft A, Stuber F (2007) Concentrations of tramadol and O-desmethyltramadol enantiomers in different CYP2D6 genotypes. Clin Pharmacol Ther 82:1-7. doi: $10.1038 /$ sj.clpt.6100152

Sun-Edelstein C, Tepper SJ, Shapiro R (2008) Drug-induced serotonin syndrome: a review. Expert Opin Drug Saf 7:87-96. doi:10.1517/ 14740338.7.5.587
Urban BW, Bleckwenn M, Barann M (2006) Interactions of anesthetics with their targets: non-specific, specific or both? Pharmacol Ther 111:729-770. doi:10.1016/j.pharmthera.2005.12.005

White PF, Way WL, Trevor AJ (1980) Pharmacology of ketamine isomers in surgical patients. Anesthesiology 52:231239

Wittmann M, Peters I, Schaaf T, Wartenberg HC, Wirz S, Nadstawek J, Urban BW, Barann M (2006) The effects of morphine on human 5HT3A receptors. Anesth Analg 103:747-752. doi:10.1213/01.ane. 0000229706.84471.4d

Wittmann M, Schaaf T, Peters I, Wirz S, Urban BW, Barann M (2008) The effects of fentanyl-like opioids and hydromorphone on human 5-HT3A receptors. Anesth Analg 107:107-112. doi:10.1213/ane. 0b013e31817342c2 